\title{
Black mark for Dalhousie medical school
}

Published at www.cmaj.ca on Oct. 23

$\mathrm{T}$ he Dalhousie University undergraduate medical program has failed to avert accreditation probation. The Halifax, Nova Scotia-based medical school on Oct. 14 lost its appeal before the American-based Liaison Committee on Medical Education and was placed on two years probation for failing to meet the accrediting requirements.

Probationary status obligates Dalhousie to notify all enrolled students and all applicants that the program is not completely in good graces with accrediting authorities.

"It's a reputational black mark," says Dr. Tom Marrie, dean of the medical school.

But the school can continue to qualify doctors and provide residency training, Marrie adds. "The program is still a good program. It's still accredited."

The program was jointly reviewed earlier this year by the Liaison Committee on Medical Education and the Committee on Accreditation of Canadian Medical Schools. The Canadian team found the school noncompliant in 12 of 132 measures and indicated it would return in a year to assess progress. The American team, however, determined that Dalhousie was noncompliant in 17 areas and opted not to issue an accreditation seal of approval. Issues identified by the American team related mainly to curriculum management, monitoring and evaluation. Failing grades were also given for failing to upgrade computer databases and for failing to provide the school's chief administrative officer with sufficient resources and authority to manage and assess the curriculum (CMAJ 2009. DOI:10.1503/cmaj.109-3019).

Marrie also indicated that Dalhousie is hoping to regain good standing by undertaking an overhaul of its curriculum. Some 20 groups have been established to explore best practices in medical education and are scheduled to report back this fall. Many of the committee members are physicians and

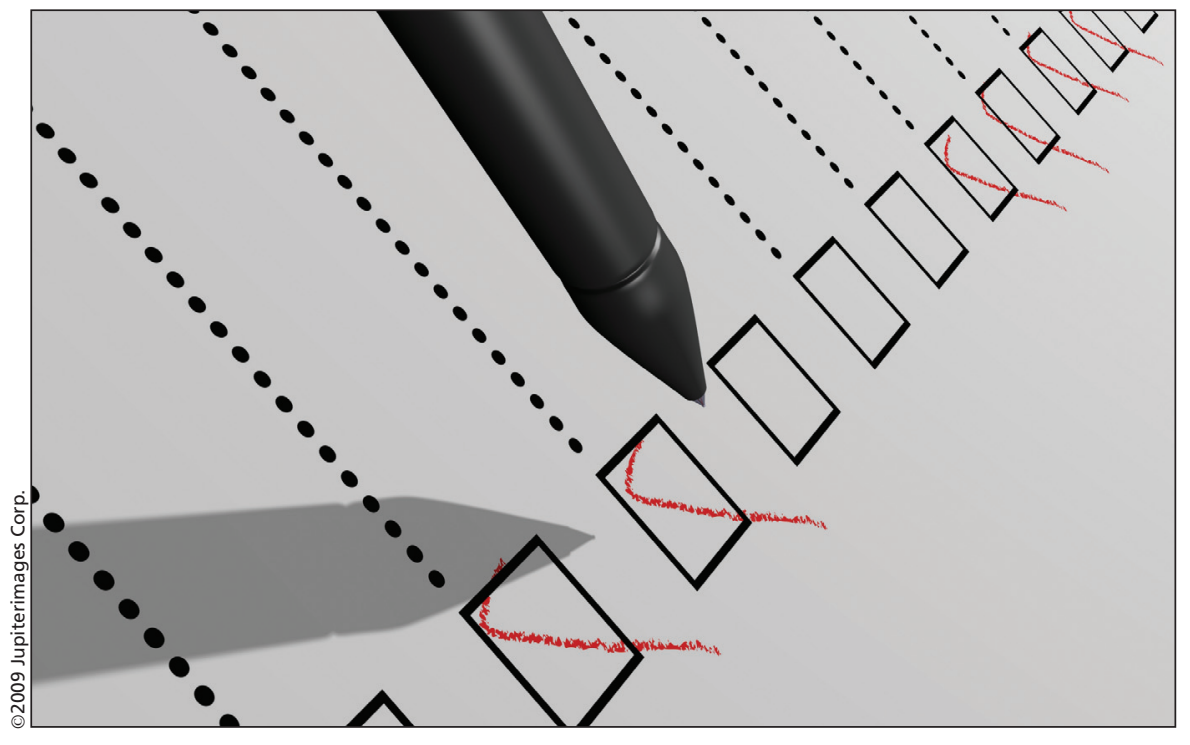

The Dalhousie University undergraduate medical program failed to receive passing grades in 10 areas, including its curriculum, according to the American-based Liaison Committee on Medical Education.

government employees who have volunteered their time, Marrie says. "The response has been overwhelming."

Dalhousie's response has assuaged the concerns of the medical community, says Dr. Ross Leighton, president of Doctors Nova Scotia.

"Dalhousie Medical School is an integral part of the health care system, and we'd like to be certain that it's offering the highest quality education possible," Leighton says.

"I've been assured by colleagues and the university that all necessary steps are being taken to improve the status of the medical school," he adds. "It's my understanding that since the university was notified of the potential for probation, 200 staff have been working to get things in order."

Marrie also expressed a measure of confusion over the decision to officially place Dalhousie on probation.

The US accrediting body had identified 17 areas in which Dalhousie's program was deemed deficient. In the runup to Dalhousie's appeal, seven of those were overturned, leaving Dalhousie deficient in 10 areas.
Marrie said that while Dalhousie was able to convince the appeal committee that it deserved a passing grade in areas like making its educational objectives known and providing the chief administrative officer with sufficient resources to manage and assess the curriculum, the committee still decided to give the program an "F" grade. It did not accept Dalhousie's argument that it offered a comparable educational experience across all of its sites or that it had an effective system to assist students in making a career choice.

Marrie also indicated that Dalhousie will use its probationary status as an impetus for reform. The school will host a symposium on medical education, from which will emerge a new curriculum for the incoming class of 2010. "We expect we'll exceed current LCME [Liaison Committee on Medical Education] standards and be on the leading edge of undergraduate medical education in Canada." - donalee Moulton, Halifax, NS

DOI:10.1503/cmaj.109-3088 